\title{
Neurological manifestations and comorbidity associated with COVID-19: an overview
}

\author{
Mukesh Kumar $^{1,2} \cdot$ Ajit Kumar Thakur ${ }^{1}$ (i) \\ Received: 21 August 2020 / Accepted: 10 October 2020 / Published online: 14 October 2020 \\ (C) Fondazione Società Italiana di Neurologia 2020
}

\begin{abstract}
First in 2002, severe acute respiratory syndrome coronavirus (SARS-CoV), second in 2012, Middle East respiratory syndrome coronavirus (MERS-CoV), and now the third in the December 2019, emergence of tremendously pathogenic and large-scale epidemic novel coronavirus (SARS-CoV-2) has brought the worst conditions into the human inhabitants of the twenty-first century. The SARS-CoV-2 uses the resembling receptor, angiotensin-converting enzyme 2 (ACE2) as that for SARS-CoV, and mainly feasts through the respiratory tract. The ACE2 receptor appearances have been also detected upon glial cells and neurons, which makes them a potential target of SARS-CoV-2 disease (COVID-19). Consequently, cells expressing ACE2, apart from lung and cardiovascular tissue, neurons and glial cells may act as targets and are thus vulnerable to SARS-CoV-2 systemic infection as well as its central nervous system (CNS) comorbidities. Investigation of the neurological manifestations of COVID-19 is a step towards better understanding the SARS-CoV-2 infections, inhibiting the additional spread and treating patients affected by this pandemic. In this concern, more clinical examinations for CNS involvement of SARS-CoV-2 are warranted. In this article, we have reviewed the neurological characteristic features of COVID-19 patients, latent neurotropic mechanisms of SARS-CoV-2 involvement in the comorbidity associated with CNS disorders, and neurological manifestations associated with COVID-19. Therefore, in the perspective of COVID-19 pandemic, clinicians and healthcare workers should be aware of a wide spectrum of neurological manifestations associated with COVID-19 along with their signs and symptoms for initial diagnosis and isolation of the patients.
\end{abstract}

Keywords SARS-CoV-2 · COVID-19 · Angiotensin-converting enzyme $2 \cdot$ Comorbidities $\cdot$ Neurological manifestations

\section{Introduction}

One of the most contagious viruses is coronavirus (Family: Coronaviridae), primarily targeting the human respiratory system and infecting the epithelial cells of the respiratory tract, but it also has neuroinvasive capabilities to spread from the respiratory tract to the central nervous system (CNS) $[1,2]$. Earlier epidemics or pandemics of coronaviruses comprise the severe acute respiratory syndrome (SARS-CoV) during 2002 and Middle East respiratory syndrome (MERS-CoV) during

Ajit Kumar Thakur

ajit.thakur@dpsru.edu.in

1 Neuropharmacology Research Laboratory, School of Pharmaceutical Sciences, Delhi Pharmaceutical Sciences and Research University, New Delhi 110 017, India

2 Indian Pharmacopoeia Commission, Ministry of Health \& Family Welfare, Government of India, Ghaziabad, Uttar Pradesh 201002 , India
$2012[3,4]$. The present pandemic is an acute respiratory disease, caused by a novel coronavirus (SARS-CoV-2, earlier known as 2019-nCoV); the SARS-CoV-2 disease 2019 (COVID-19) was spread throughout China and rapidly acknowledged the global attention. On 30 January 2020, the World Health Organization (WHO) officially stated the COVID-19 epidemic as a public health emergency of global concern. The symptoms of COVID-19 infection habitually appear after an incubation period most commonly around 5 days (range from 1 to 14 days) [5].

The most common symptoms of COVID-19 illness are fever, cough, and fatigue; other symptoms include headache, hemoptysis, and dyspnea, among others. In the most severe cases, patients may develop pneumonia, acute respiratory distress syndrome, acute cardiac problems, and multi-organ failure $[2,6]$. The first cases of COVID-19 were reported in December 2019 [7]. The appearance of SARS-CoV-2 marked the third introduction of extremely pathogenic and large-scale epidemic coronavirus into the human inhabitants after SARS$\mathrm{CoV}$ and MERS-CoV [8]. The elderly and people with 
underlying diseases are more susceptible to infection and prone to serious outcomes, which may be related with acute respiratory distress syndrome (ARDS) and cytokine storm $[9,10]$.

The COVID-19 pandemic is of great global public health concern in the twenty-first century. Special attention and efforts should be applied to prevent and reduce the transmission in susceptible populations, including children, elderly people, and healthcare providers [6]. Recently, several reports on meningitis, encephalitis, myelitis, and peripheral nerve affection in the context of COVID-19 were published, suggesting that SARS-CoV-2 can directly or indirectly infect structures and functions of the nervous system [11-20]. Coronavirus infections have been associated with the neurological manifestations, viz., febrile seizures, convulsions, change in mental status, and encephalitis [21].

In a recently published systemic review, the neurotropic and neuroinvasive abilities of coronaviruses in humans have been described [2]. A growing body of evidence shows that neuroinvasion and neurotropism is a common feature of human coronaviruses. The neuroinvasive human viruses, respiratory viruses, may damage the CNS as a result of misdirected host immune responses that could be associated with autoimmunity in susceptible individuals (virus-induced neuro-immunopathology) and/or viral replication, which directly causes damage to CNS cells (virus-induced neuropathology) [1, 2]. Coronavirus enters through nasal infection and reached to the CNS through the olfactory bulb, causing neuro-inflammation and demyelination of neuronal cells [9]. It has also been reported and correlated that the patients infected with SARSCoV-2 show encephalopathy and neuro-inflammation resulting from a cytokine storm [22]. Therefore, exploring the neurologic manifestations associated with COVID-19 is urgently required for better understanding the SARS-CoV-2 brain infections, inhibiting the additional spread and treating patients affected by this pandemic. In this review, we have explored the epidemiology and pathophysiology of COVID19 , their comorbidity in brain disorders, and neurological manifestations reported.

\section{COVID-19: epidemiology and pathophysiology}

Coronaviruses are enveloped, pleomorphic, spherical particles, 150 to $160 \mathrm{~nm}$ in size, positive-sense single-stranded viruses ((+) ssRNA virus) belonging to the family Coronaviridae, and containing 8-10 open reading frames (ORFs) [23]. ORF1a and ORF1b are translated into polyprotein 1a and polyprotein $1 \mathrm{ab}$, which are processed by viral proteases to produce 16 nonstructural proteins containing RNA-dependent RNA polymerase enzyme (RdRp). The viral RNA is replicated via transcription of a minus-strand template by RdRp. Coronaviruses generate 6-9 subgenomic mRNAs (sgmRNAs) during replication, which lead to translation of accessory and physical proteins from downstream ORFs. Spike (S), envelope (E), membrane $(\mathrm{M})$, and nucleocapsid $(\mathrm{N})$ proteins are required for completion of a viral replication cycle, and these proteins translated from sgmRNAs [24-27].

The antibodies generated against the $\mathrm{N}$ protein of SARSCoV may cross counter with COVID-19; however, the heterophilic antibodies of SARS-CoV may not afford cross protection to COVID-19, though it can be used for diagnostic purposes [23]. An additional possible role of SARS-CoV-N protein is its capability to counter host immune response as a viral suppressor protein of RNAi (VSR) [28]. The VSRs suppress the RNAi at the pre-dicer or post-dicer level to overcome the host defense to establish infection [23]. In a Clustal W analysis of N-protein of SARS-CoV and COVID-19 by NCBI amino acid blast, it is demonstrated and reported that more than $90 \%$ sequence identity were similar in SARS-CoV and COVID-19. So, the N-protein of COVID-19 may act in an analogous fashion to SARS-CoV as a VSR to counter the host defense mechanism [23].

COVID-19 has significant consequences for morbidity and mortality worldwide since December 2019. To explore the effects of comorbid chronic diseases on clinical outcomes of COVID-19, it was found that diabetes present in 10\%, coronary artery disease/cardiovascular disease (CAD/CVD) was in $8 \%$, and hypertension was in $20 \%$, which were much higher than that of $3 \%$ chronic pulmonary disease [29]. The occurrence of a core and receptor-binding domain (RBD) from the crystal structure of SARS-CoV-2 has exposed that is more closely involved in recognizing the hACE2. Although SARS-CoV and SARS-CoV-2 both exploit the same receptor hACE2 in humans to gain entry into the host, the SARS-CoV2 binding is more compacted by a four-residue motif from 482 to 485 in the hACE2 ridge, thus improving the binding affinity of SARS-CoV-2 over SARS-CoV for hACE [30]. Moreover, the two viral hot spots, namely, hot spot-31 and hot spot-353 on hACE2, are stabilized more by the SARS-CoV-2 RBD as compared to SARS-CoV. All this clearly indicates why SARS-CoV-2 has a selective advantage over SARS-CoV in causing infection and is a more evolved and lethal strain [22].

The key clinical manifestation of SARS-CoV-2 is severe pneumonia causing immense respiratory distress in the patients, especially the aged or those with already pre-existing conditions. SARS-CoV-2 leads to chronic inflammation of the lungs, severe dyspnea, fever, dry cough, and cyanosis and in more vulnerable patients a complete lung failure. ACE2, which is the entry point for SARS-COV-2, has almost an ubiquitous presence in human organs including lung parenchyma, gastrointestinal tract, nasal mucosa, renal and urinary tract, human airway epithelia, vascular endothelium, lymphoid tissues, reproductive organs, as well as in brain [31]. The virus is expected to enter chiefly through the nasal 
mucosa or the gastrointestinal tract due to their higher expression of protein hACE2. The exciting part though is that recently reported studies have noted altered mental health in some COVID-19 patients $(n=214)$ showing symptoms like anosmia (5.1\%) and ageusia (5.6\%) without nasal obstruction or other rhinitis symptoms, thereby indicating a neuroinvasive nature of the virus [16, 32-34].

Specifically, pre-existing chronic conditions are strongly correlated with disease severity and being admitted to intensive care unit also, compared to COVID-19 patients with no pre-existing chronic diseases. COVID-19 patients who present with diabetes, hypertension, $\mathrm{CAD} / \mathrm{CVD}$, or chronic pulmonary disease have a higher risk of developing severe disease, respectively. Surprisingly, the authors found no correlation between chronic conditions and increased risk of mortality (OR 2.09 , 95\% CI 0.26 to 16.67 ) [29]. Engaged together, cardio-metabolic diseases, such as diabetes, hypertension, and $\mathrm{CAD} / \mathrm{CVD}$, were more common than chronic pulmonary disease in COVID-19 patients. However, each comorbid disease was correlated with increased disease severity, and after an active treatment, increased risk of mortality in patients with pre-existing chronic diseases may reduce [29].

The ACE2 receptor expression in the brain has been also reported and detected over glial cells and neurons, which makes them a potential target of COVID-19 systemic infection as well as its CNS comorbidities. Thus, cells exposing ACE2, such as neurons and glial cells, may act as targets and are thus susceptible to SARS-CoV-2 infection [35]. It is possible that SARS-CoV-2 could infect the brain through olfactory nerves located in the nasal cavity, like other neurotropic coronaviruses. Moreover, it is also suggested that respiratory failure in severe COVID-19 cases might be treated from the perspective of the CNS [36]. In an independent prospective clinical study, it was concluded that neurological symptoms are often seen in patients with COVID-19. Moreover, the headache was the most commonly seen neurological symptom in this disease along with dizziness, impaired consciousness, smell and gustation impairments, cerebrovascular disorders, epileptic seizures, and myalgia [37].

\section{CNS comorbidity and psychiatric disorders}

The psychiatric disorders are common in several neurological disorders, e.g., Alzheimer's disease, Parkinson's disease, epilepsy, migraine, essential tremor, and stroke. These comorbidities increase disease load and may complicate the treatment of mutual disorders. Early studies of the comorbidity of psychiatric and neurological disorders were cross-sectional, and the time order of the relatives was not possible to elucidate [38]. The latest work has clarified time associations between psychiatric disorders and neurological disorders, particularly in epilepsy and stroke where epidemiological evidence recommends that there is a bidirectional relationship [39]. Though these associations are understood in many neurological disorders, repetitive screening for psychiatric disorders in such cases is infrequent, mostly due to the lack of partnerships between psychiatrists and neurologists and the paucity of neuropsychiatrists [38]. Various evidences have been reported and support the possible CNS comorbidities associated with COVID-19 pathophysiology [1, 2, 11-22]. Therefore, the healthcare provider should be aware of the wide spectrum of neurological sign and symptoms associated with COVID-19 for early diagnosis and isolation of the patients [40]. Apart from these, much more prerequisites should be done to improve the finding and treatment of COVID-19 patients suffering from neurological and psychiatric disorders and their comorbidities after SARSCoV-2 infection. There is also a need to understand the prospect of these comorbidities which may motivate alliances to improve the lives of the publics affected by neurological and psychiatric disorders associated with COVID-19.

\section{Encephalopathy in COVID-19}

The neurological manifestations of SARS-CoV-2 have been recently recognized from computed tomography $(\mathrm{CT})$ and magnetic resonance imaging (MRI) images of the brain of a patient who contracted COVID-19 and showed symptoms of necrotizing hemorrhagic encephalopathy [13]. A rare disorder such as acute necrotizing encephalopathy (ANE) is leading to brain dysfunction generally caused by viruses, which outcomes in liver problems, seizures, mental disorientation, and subsequent infection. This sickness is categorized by multifocal symmetric lesions in the brain that influence the brain stem, thalami, cerebellum, and cerebral white matter. The causes of ANE is neuro-inflammation resulting from a cytokine storm characterized primarily by the creation of the interleukin-6 (IL-6), secreted by the macrophages, which have been activated by the granulocyte-macrophage colony-stimulating factor (GM-CSF) produced by the helper T cells [22]. The resultant cytokine storm may also cause a surge in interleukin (IL)-2, IL-7, interferon- $\gamma$, inducible protein 10, monocyte chemo attractant protein 1 , macrophage inflammatory protein $1-\alpha$, and tumor necrosis factor- $\alpha$ leading to hyperinflammation [10]. The systemic inflammation causes severe encephalopathy in the patient, and that may lead even to stroke. In the patient, specifically infected with SARSCoV-2 showing ANE, the MRI images displayed clear evidence of hemorrhage through hypointense signal intensity in the susceptibility-weighted images and increase in the rim on the post contrast images [22].

\section{Neuroinvasion of SARS-CoV-2}

As a pandemic virus, no effective treatment has been established until date for this disease resulting from SARS- 
CoV-2. Thus, awareness of the possible entry and pathogenicity of SARS-CoV-2 into the CNS will have important guiding significance for the prevention and treatment of COVID-19. To identify the possible routes by which this virus invades the CNS, several studies have been postulated for the olfactoryhematogenous pathway, trans-neuronal machinery, and lymphatic pathway, as putative routes of coronavirus entry into the CNS [1, 19]. If the neuroinvasion of SARS-CoV-2 gets a part in the extension of respiratory failure in COVID-19 patients, the precaution with masks will absolutely be the most efficient measure to defend against the possible entry of the virus into the CNS [41]. It might be estimated that the indication of the patients infected via conjunctiva will be lighter than those infected intranasally. The probable neuroinvasion of SARS-CoV-2 may also partially explain why some patients developed respiratory failure, while others not. As SARS$\mathrm{CoV}-2$ may conceal itself in the neurons from the immune recognition, complete clearance of the virus may not be sure even the patients have recovered from the acute infection [41]. In sustain of this, there is evidence that SARS-CoV-2 is still detectable in some patients during the convalescent period. So, given the probable neuroinvasion, the risk of SARSCoV-2 infection may be currently underestimated [31]. It is also a prerequisite to find effective antiviral drug therapies that can cross the blood-brain barrier to prevent and treat CNS infections from SARS-CoV-2.

Currently, as encephalopathy also has been identified as one of the symptoms of COVID-19 [13], therefore, neuroinvasiveness of SARS-CoV-2 needs to be evaluated to fully understand the neurological implications of COVID-19. The brain reportedly, like most other organs, expresses the hACE2 considered to be the entry point of the SARS-CoV-2 viruses in humans and is therefore not immune to viral infection [22]. Though SARS-CoV-2 is yet to be detected in cerebrospinal fluid, SARS-CoV with similar structural and functional features has been detected in the cerebrospinal fluid of patients, indicating the ability of the virus to breach the extremely rigid blood-brain barrier [31]. If prior studies with other CoVs are taken into consideration, then SARS-CoV-2 like its other family members will first infect the peripheral nerve terminals and then slowly crawl its way through the synapse-connected route into the CNS [42]. The associated field with SARS-CoV and MERS-CoV earlier studies observed that they infiltrate the brains of transgenic mice when administered intranasally. The virus through infiltrates into the brain took place via the olfactory nerves, ultimately affecting the thalamus and the brain stem [31].

The brain stem has been observed and reported as worst infected in COVID-19 patients. Several reports warranted for subsequent investigational studies along with the hematologic spread of SARS-CoV-2 in CNS as well as retrograde neuronal transport from the lungs into the CNS through vagal nerve afferents must be taken into consideration [31, 42-44]. Also, with reports appealing infection of the gastrointestinal tract by SARS-CoV-2, the virus could even use the enteric nervous system and its sympathetic afferent neurons to reach the CNS. Now, with the reports of spontaneous breathing, hyposmia, and ageusia in COVID-19 patients, scientists have started to speculate that not only does SARS-CoV-2 infects lungs but it has severe implications in neurons, specifically those in the medulla oblongata, which regulates breathing, lung, and heart functions, and any damage to it can result in chronic respiratory distress as reported in COVID-19 patients [22]. It has been put forward that the latency period of the virus may be enough to destroy the neurons in the medullary region of the brain and can lead to coma or death. As reports of SARS$\mathrm{CoV}-2$ reaching the blood-brain barrier through the circulating blood and breaching it by attacking the endothelial layer to gain access to CNS emerge, the virus might just be using an alternating route in the form of the olfactory bulb instead of the common hematological route $[1,19]$. The neuronal cells infected with the virus, immune systems (microphase, T cells, and monocytes) triggered, and inflammatory system activated leads to cytokine storm and oxidative stress (Fig. 1). If this is to be measured, the virus might just be making its way into olfactory mucosa, mostly consisting of olfactory neurons along with blood vessels and epithelial cells [22]. The olfactory mucosa relates to the olfactory bulb through the cribriform plate, which is found at the very base of the frontal lobes of the brain [16]. This very much elucidates the hyposmia and other neurological symptoms that are being increasingly observed in COVID-19 patients. The fact to note here is that the long-term effects of the neuroinvasive nature of the virus may result in an increased risk of neurodegenerative diseases with involvement in the pathogenesis of neurological disorders like Parkinson's disease and multiple sclerosis [42]. Further, the conditions are more likely to be worsened in COVID-19 patients with pre-existing neurological disorders [22].

\section{Neurological manifestations of COVID-19}

Neurological manifestations in COVID-19 patients generally arise between 1 and 14 days after the beginning of SARS$\mathrm{CoV}-2$ infectious symptoms, and it has been predicted on average of 5-day incubation period (time between infection and symptoms onset) [45]. The SARS-CoV-2 is a singlestranded RNA coronavirus, the genome of which has $89.1 \%$ similarity in its nucleotide sequence to a group of SARS-like coronaviruses. It has been classified as the genus Betacoronavirus, subgenus Sarbecovirus, and is the seventh member of the coronavirus family that can infect humans [35]. Naturally, common cold symptoms are caused by these four human coronaviruses, viz., NL63, HKU1, 229E, and OC43, whereas the three others are accountable for several pandemic infectious diseases, such as SARS in 2002 (SARS-CoV), 
MERS in 2012 (MERS-CoV), and COVID-19 (SARS-CoV2) in $2019[7,46]$.

The neurological manifestations reported by SARS patients, SARS-CoV was detected in samples/specimens of SARS patients. CSF samples of a SARS patient who presented generalized tonic-clonic convulsion tested positive for SARS-CoV, suggesting possible infection of the CNS by SARS-CoV [18]. The SARS-CoV was isolated from a sample of brain tissue of one patient with SARS that had presented severe CNS symptoms, and pathological examination of the brain tissue showed neuronal necrosis and glial cell hyperplasia $[15,35]$. Furthermore, SARS viral particles and its genomic sequence were detected in the neurons in the brains of all eight confirmed cases of SARS autopsies. Of these, six confirmed cases presented edema and scattered red degeneration of the neurons [47].

The reported prevalence of neurologic manifestations associated with COVID-19 patient is $36.4 \%$ in China and $57.4 \%$ in
Europe $[32,48]$. In a recent published report from hospital network in Chicago, Illinois, out of total 509 patients, neurologic manifestations were present at COVID-19 onset in 215 (42.2\%), at hospitalization in $319(62.7 \%)$, and at any time during the disease course in 419 patients $(82.3 \%)$. Furthermore, it was explained and reported in an independent study that the most frequent neurologic manifestations in COVID-19 patients were myalgias (44.8\%), headaches (37.7\%), encephalopathy (31.8\%), dizziness $(29.7 \%)$, dysgeusia (15.9\%), and anosmia (11.4\%) [49]. The aspect for these differences in frequencies of neurologic manifestations might be due to genetic factors including polymorphism in expression of the viral receptor ACE2 in the nervous system and, possibly, SARS-CoV-2 strain variations [50].

The first case of meningitis/encephalitis associated with SARS-CoV-2 was reported from the Yamanashi University Hospital, Japan [11]. The SARS-CoV-2 RNA was detected in the CSF specimen that confirms direct evidence of the
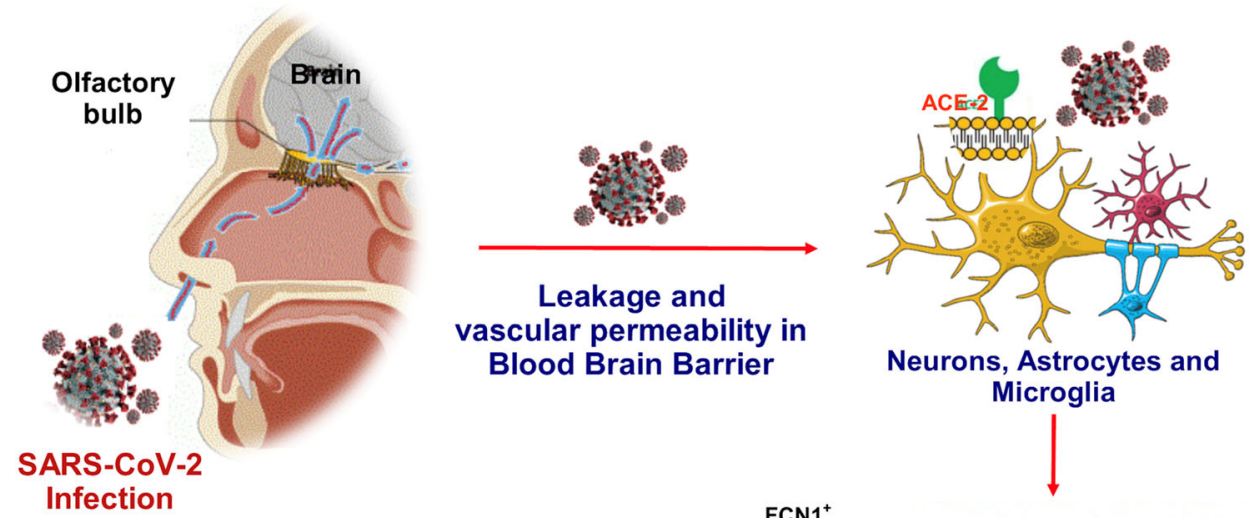

Neurons, Astrocytes and Microglia

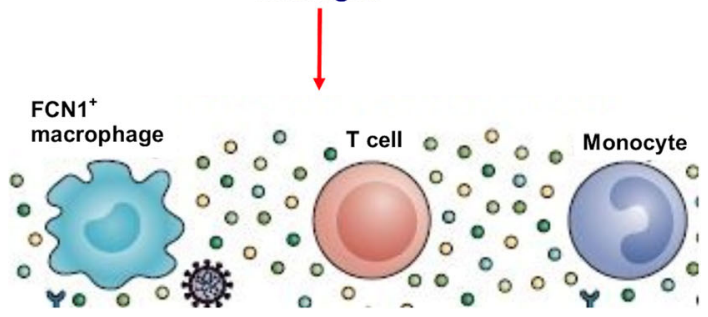

Dysfunctional immune response and
excessive infiltration of monocytes,
macrophages and T-cells in Brain

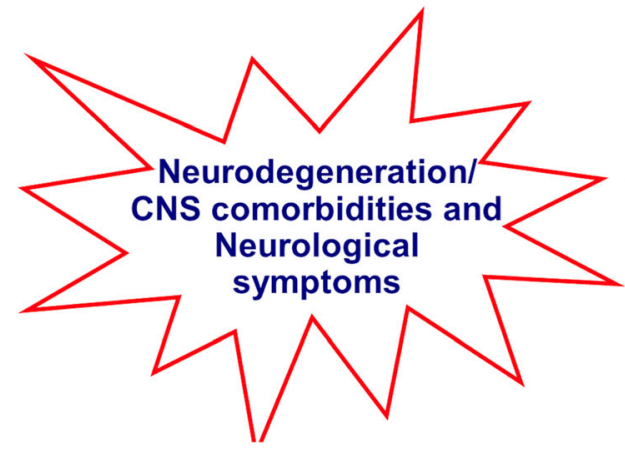

Fig. 1 Neurodegenerations and CNS comorbidities associated with COVID-19. SARS-CoV-2 reaching the blood-brain barrier through the circulating blood and breaching it by attacking the endothelial layer to gain access to CNS emerges. The neuronal cells infected with virus, immune systems (microphase, $\mathrm{T}$ cells, and monocytes) triggered, and inflammatory system activated leads to cytokine storm, oxidative stress, and associated neurological manifestations 
neuroinvasiveness of SARS-CoV-2 [11, 35]. In addition to this, the pathological findings in brain tissue of COVID-19 patients, diagnosed on the 13th day of hospital admission, have been reported in the gross anatomy of a patient admitted because of cerebral infarction. However, only non-specific brain edema and atrophy without further histopathological observations were found by gross anatomical examination of this patient and without any signs of infection. Thus, detailed neurological examination and attempts to separate SARS$\mathrm{CoV}-2$ from the neuronal tissue are required to provide direct neurotropic evidence of SARS-CoV-2 [16].

In a recent review [51], authors have categorized the reported neurological findings related to COVID-19 into three categories:

a) Central (headache, dizziness, impaired consciousness, acute cerebrovascular disease, ataxia, seizures, and special senses)

b) Peripheral (hypogeusia, hyposmia)

c) Musculoskeletal (ischemic or hemorrhagic)

Apart from the above, increasing evidence indicated that coronaviruses may invade the CNS, causing neurological disorders. Though headache has been the most common neurological manifestations reported by COVID-19 patients [52, 53], a systematic review of COVID-19 patients concluded that the mean prevalence of headache was only $8 \%$ (95\% CI $5.7-10.2 \%$ ) [54]. Apart from headache, dizziness is also a common neurological manifestations of COVID-19, with a reported prevalence of between 7 and 9.4\% [55, 56]. In an independent study, authors have reported that out of total 138 admitted patients in hospital, those who required ICU care $(n=36)$ were more likely to report dizziness than those who did not $(n=102)$ (ICU 8/36 [22.2\%] vs. nonICU 5/102 [4.9\%], $P=0.007)$. Confusion and headache were the fifth $(9 / 99$ [9\%]) and sixth $(8 / 99$ [8\%]) most common symptoms of the COVID-19 patients $(n=99)$ at admission, respectively [57]. Furthermore, it has recently been reported that several cases of COVID-19 have concurrent severe neurological symptoms, such as acute CVD (acute ischemic stroke, cerebral venous sinus thrombosis, cerebral hemorrhage, subarachnoid hemorrhage), meningitis/encephalitis, acute necrotizing hemorrhagic encephalopathy, and acute Guillain-Barré syndrome [11, 58].

In another study with COVID-19 patients $(n=214), 78$ (36.4\%) patients had neurological manifestations. Furthermore, compared with non-severe patients, severe patients were more likely to have neurological symptoms (40 [45.5\%] vs 38 [30.2\%], $P<0.05)$, such as acute CVD (5 [5.7\%] vs $1[0.8 \%], P<0.05)$, impaired consciousness (13 [14.8\%] vs 3 [2.4\%], $P<0.001)$, or skeletal muscle injury
(17 [19.3\%] vs 6 [4.8\%], $P<0.001)$. As per this report, the most common neurological manifestation was dizziness (36 [16.8\%]), followed by headache (28 [13.1\%]), impaired consciousness (16 [7.5\%]), acute CVD (6 [2.8]), ataxia (1 $[0.5 \%])$, and seizure $(1[0.5 \%])$. In addition, symptoms involving the cranial nerves, such as hypogeusia, hyposmia, hypopsia, and neuralgia, have also been reported in 19 $(8.9 \%)$ patients $[32,35]$.

An observational study was done with 6147 COVID-19 patients in Fars province, Iran, for the occurrence of seizures in patients with COVID-19 and to clarify the circumstances of the occurrence of seizures in these patients. Although authors have found seizure rate $0.08 \%(n=5)$, they concluded the new-onset seizures in critically ill patients with COVID-19 should be considered as acute symptomatic seizures [59].

As recognition of the disease has developed, the reported incidence of chemo-sensitive impairment (loss of taste and smell) in COVID-19 has been considerably higher than in the initial stages, ranging from 19.4 to $88 \%$ [33, 60]; also, as stated by Bookstaver et al., the clinical symptoms of viral infection are usually nonspecific and sometimes may be mild or symptomless [17]. Therefore, the prevalence of neurological manifestations was very likely underestimated in the early stages of the COVID-19 outbreak [17, 33, 61]. However, CVD is among the most prevalent comorbidities of COVID-19 patients, especially in severe cases. Chen et al. reported that cardiovascular and cerebrovascular diseases were the most prevalent (40/99; $40 \%)$ chronic underlying conditions [57]. They have reported that out of total 138 hospitalized patients, CVD $(7 / 138,5.1 \%)$ ranked fifth among the most common comorbidities, while the first to fourth comorbidities were hypertension $(43 / 138,46.4 \%)$, cardiovascular disease $(20 / 138,14.5 \%)$, diabetes $(14 / 138,10.1 \%)$, and cancer $(10 / 138,7.2 \%)$. ICU patients were also more likely to have CVD than non-ICU patients (ICU 6/36 [16.7\%] vs non-ICU 1/102 [1.0\%], $P=0.001$ ) [55]. Furthermore, coronary heart disease as well as CVD has been confirmed to be independent risk factors associated with fatal outcomes [62]. Most of the reported COVID-19 patients from these observations are explainable as have been elderly (age $\geq 50$ years old, $70 \%$ ) who are statistically more likely to have comorbidities and thus more likely to progress into severe cases $[63,64]$. Additionally, elderly patients' CNS comorbidities might not be underestimated rather more studies are warranted through clinical examinations for CNS involvement of SARS-CoV-2.

It has been reported that SARS-CoV-2-infected children tend to have a milder COVID-19 disease with lower mortality [65]. However, the occurrence of underlying neurological 
disorder or CNS comorbid condition may predispose them for severe COVID-19 manifestations [66]. Furthermore, children with neuromuscular disorders are high-risk patients for severe COVID-19 disease. Neuromuscular disorders exuberated the conditions related to respiratory muscle weakness, tracheostomy, non-invasive or invasive ventilation, weak cough, and compromised airway clearance and predispose for severe COVID-19 conditions [67]. In a case-series study, AbdelMannan et al. found that out of the 27 children with COVID-19 pediatric multisystem inflammatory syndrome, 4 patients $(14.8 \%)$ who were previously healthy had new-onset neurological symptoms. Symptoms included encephalopathy, headaches, brainstem and cerebellar signs, muscle weakness, and reduced reflexes. Authors have concluded that children with COVID-19 presented with new neurological symptoms involving both the central and peripheral nervous systems and splenial changes on imaging, in the absence of respiratory symptoms. However, they have warranted additional research to assess the association of neurological symptoms with immune-mediated changes among children with COVID-19 as well as close neurodevelopmental surveillance is required to assess the neurological and cognitive outcomes in these patients [68]. Therefore, in view of the above reported neurological manifestations associated with COVID-19, further studies should be carried out to gather evidences on the best therapeutic and management options of COVID-19 and associated comorbidities. However, at present, prevention aimed on reducing transmission in the community remains the only proven efficient option to combat COVID-19, until the pharmacotherapies and/or vaccines are developed.

\section{Concluding remarks}

During the current context of the COVID-19 pandemic, clinicians and healthcare workers should be aware of a wide spectrum of neurological manifestation associated with COVID-19 along with their signs and symptoms for initial diagnosis and isolation of the patients. There are increasing evidences that indicated that coronaviruses may invade the CNS and exuberated neurological disorders. An increasing number of reports and inclusive clinical data have been emerged out for COVID-19 patients of different age groups with severe neurological symptoms. Moreover, further clinical studies still needed to bring a reasonable concern of SARS-CoV-2, being a new neuropathogenic agent that remains underdiagnosed. Therefore, exploring the neurologic manifestations of COVID-19 is a stage towards better understanding the SARS-CoV-2 infections, avoiding further spread, and treating patients affected by this pandemic. In this concern, more clinical studies are warranted to elucidate a possible impact of SARS$\mathrm{CoV}-2$ infection on common neurodegenerative diseases, such as Alzheimer's, Parkinson's disease, or multiple sclerosis.
Acknowledgments Authors would like to acknowledge the Delhi Pharmaceutical Sciences and Research University, New Delhi, for providing needful infrastructure and facilities in writing this article.

\section{Compliance with ethical standards}

Conflict of interest The authors declare that they have no conflict of interest.

Ethical approval This is a review article, no human or animals ethical approval required.

Informed consent Not applicable. This is not a study.

\section{References}

1. Desforges M, Le Coupanec A, Dubeau P, Bourgouin A, Lajoie L, Dube M, Talbot PJ (2019) Human coronaviruses and other respiratory viruses: underestimated opportunistic pathogens of the central nervous system? Viruses 12. https://doi.org/10.3390/ v12010014

2. Asadi-Pooya AA, Simani L (2020) Central nervous system manifestations of COVID-19: a systematic review. J Neurol Sci 413: 116832. https://doi.org/10.1016/j.jns.2020.116832

3. de Wit E, van Doremalen N, Falzarano D, Munster VJ (2016) SARS and MERS: recent insights into emerging coronaviruses. Nat Rev Microbiol 14:523-534. https://doi.org/10.1038/nrmicro. 2016.81

4. Mori I, Nishiyama Y, Yokochi T, Kimura Y (2005) Olfactory transmission of neurotropic viruses. J Neuro-Oncol 11:129-137. https:// doi.org/10.1080/13550280590922793

5. Lauer SA, Grantz KH, Bi Q, Jones FK, Zheng Q, Meredith HR, Azman AS, Reich NG, Lessler J (2020) The incubation period of coronavirus disease 2019 (COVID-19) from publicly reported confirmed cases: estimation and application. Ann Intern Med 172:577582. https://doi.org/10.7326/M20-0504

6. Rothan HA, Byrareddy SN (2020) The epidemiology and pathogenesis of coronavirus disease (COVID-19) outbreak. J Autoimmun 109:102433. https://doi.org/10.1016/j.jaut.2020. 102433

7. Zhu N, Zhang D, Wang W, Li X, Yang B, Song J, Zhao X, Huang B, Shi W, Lu R, Niu P, Zhan F, Ma X, Wang D, Xu W, Wu G, Gao GF, Tan W, China Novel Coronavirus I, Research T (2020) A novel coronavirus from patients with pneumonia in China, 2019. N Engl J Med 382:727-733. https://doi.org/10.1056/NEJMoa2001017

8. Guo YR, Cao QD, Hong ZS, Tan YY, Chen SD, Jin HJ, Tan KS, Wang DY, Yan Y (2020) The origin, transmission and clinical therapies on coronavirus disease 2019 (COVID-19) outbreak - an update on the status. Mil Med Res 7:11. https://doi.org/10.1186/ s40779-020-00240-0

9. Bohmwald K, Galvez NMS, Rios M, Kalergis AM (2018) Neurologic alterations due to respiratory virus infections. Front Cell Neurosci 12:386. https://doi.org/10.3389/fncel.2018.00386

10. Mehta P, McAuley DF, Brown M, Sanchez E, Tattersall RS, Manson JJ, Hlh Across Speciality Collaboration UK (2020) COVID-19: consider cytokine storm syndromes and immunosuppression. Lancet 395:1033-1034. https://doi.org/10.1016/S01406736(20)30628-0

11. Moriguchi T, Harii N, Goto J, Harada D, Sugawara H, Takamino J, Ueno M, Sakata H, Kondo K, Myose N, Nakao A, Takeda M, Haro $\mathrm{H}$, Inoue O, Suzuki-Inoue K, Kubokawa K, Ogihara S, Sasaki T, Kinouchi H, Kojin H, Ito M, Onishi H, Shimizu T, Sasaki Y, 
Enomoto N, Ishihara H, Furuya S, Yamamoto T, Shimada S (2020) A first case of meningitis/encephalitis associated with SARS-coronavirus-2. Int J Infect Dis 94:55-58. https://doi.org/10.1016/j.ijid. 2020.03.062

12. Netland J, Meyerholz DK, Moore S, Cassell M, Perlman S (2008) Severe acute respiratory syndrome coronavirus infection causes neuronal death in the absence of encephalitis in mice transgenic for human ACE2. J Virol 82:7264-7275. https://doi.org/10.1128/ JVI.00737-08

13. Poyiadji N, Shahin G, Noujaim D, Stone M, Patel S, Griffith B (2020) COVID-19-associated acute hemorrhagic necrotizing encephalopathy: imaging features. Radiology 296:E119-E120. https://doi.org/10.1148/radiol.2020201187

14. Munz M, Wessendorf S, Koretsis G, Tewald F, Baegi R, Kramer S, Geissler M, Reinhard M (2020) Acute transverse myelitis after COVID-19 pneumonia. J Neurol 267:2196-2197. https://doi.org/ 10.1007/s00415-020-09934-w

15. Xu J, Zhong S, Liu J, Li L, Li Y, Wu X, Li Z, Deng P, Zhang J, Zhong N, Ding Y, Jiang Y (2005) Detection of severe acute respiratory syndrome coronavirus in the brain: potential role of the chemokine mig in pathogenesis. Clin Infect Dis 41:1089-1096. https:// doi.org/10.1086/444461

16. Baig AM, Khaleeq A, Ali U, Syeda H (2020) Evidence of the COVID-19 virus targeting the CNS: tissue distribution, host-virus interaction, and proposed neurotropic mechanisms. ACS Chem Neurosci 11:995-998. https://doi.org/10.1021/acschemneuro. 0c00122

17. Bookstaver PB, Mohorn PL, Shah A, Tesh LD, Quidley AM, Kothari R, Bland CM, Weissman S (2017) Management of viral central nervous system infections: a primer for clinicians. J Cent Nerv Syst Dis 9:1179573517703342. https://doi.org/10.1177/ 1179573517703342

18. Lau KK, Yu WC, Chu CM, Lau ST, Sheng B, Yuen KY (2004) Possible central nervous system infection by SARS coronavirus. Emerg Infect Dis 10:342-344. https://doi.org/10.3201/eid1002. 030638

19. Iroegbu JD, Ifenatuoha CW, Ijomone OM (2020) Potential neurological impact of coronaviruses: implications for the novel SARSCoV-2. Neurol Sci 41:1329-1337. https://doi.org/10.1007/s10072$020-04469-4$

20. Fatima N, Saqqur M, Qamar F, Shaukat S, Shuaib A (2020) Impact of COVID-19 on neurological manifestations: an overview of stroke presentation in pandemic. Neurol Sci 41:2675-2679. https://doi.org/10.1007/s10072-020-04637-6

21. Asadi-Pooya AA (2020) Seizures associated with coronavirus infections. Seizure 79:49-52. https://doi.org/10.1016/j.seizure.2020. 05.005

22. Das G, Mukherjee N, Ghosh S (2020) Neurological insights of COVID-19 pandemic. ACS Chem Neurosci 11:1206-1209. https://doi.org/10.1021/acschemneuro.0c00201

23. Kannan S, Shaik Syed Ali P, Sheeza A, Hemalatha K (2020) COVID-19 (novel coronavirus 2019) - recent trends. Eur Rev Med Pharmacol Sci 24:2006-2011. https://doi.org/10.26355/ eurrev 20200220378

24. Ahn DG, Shin HJ, Kim MH, Lee S, Kim HS, Myoung J, Kim BT, Kim SJ (2020) Current status of epidemiology, diagnosis, therapeutics, and vaccines for novel coronavirus disease 2019 (COVID-19). J Microbiol Biotechnol 30:313-324. https://doi.org/10.4014/jmb. 2003.03011

25. Li F, Li W, Farzan M, Harrison SC (2005) Structure of SARS coronavirus spike receptor-binding domain complexed with receptor. Science 309:1864-1868. https://doi.org/10.1126/science. 1116480
26. Perlman S, Netland J (2009) Coronaviruses post-SARS: update on replication and pathogenesis. Nat Rev Microbiol 7:439-450. https://doi.org/10.1038/nrmicro2147

27. Krupovic M, Koonin EV (2017) Multiple origins of viral capsid proteins from cellular ancestors. Proc Natl Acad Sci U S A 114: E2401-E2410. https://doi.org/10.1073/pnas.1621061114

28. Cui L, Wang H, Ji Y, Yang J, Xu S, Huang X, Wang Z, Qin L, Tien P, Zhou X, Guo D, Chen Y (2015) The nucleocapsid protein of coronaviruses acts as a viral suppressor of RNA silencing in mammalian cells. J Virol 89:9029-9043. https://doi.org/10.1128/JVI. 01331-15

29. Liu H, Chen S, Liu M, Nie H, Lu H (2020) Comorbid chronic diseases are strongly correlated with disease severity among COVID-19 patients: a systematic review and meta-analysis. Aging Dis 11:668-678. https://doi.org/10.14336/AD.2020.0502

30. Shang J, Ye G, Shi K, Wan Y, Luo C, Aihara H, Geng Q, Auerbach A, Li F (2020) Structural basis of receptor recognition by SARSCoV-2. Nature 581:221-224. https://doi.org/10.1038/s41586-0202179-y

31. Li YC, Bai WZ, Hashikawa T (2020) The neuroinvasive potential of SARS-CoV2 may play a role in the respiratory failure of COVID-19 patients. J Med Virol 92:552-555. https://doi.org/10. $1002 /$ jmv. 25728

32. Mao L, Jin $\mathrm{H}$, Wang $\mathrm{M}, \mathrm{Hu} \mathrm{Y}$, Chen $\mathrm{S}, \mathrm{He} \mathrm{Q}$, Chang J, Hong C, Zhou Y, Wang D, Miao X, Li Y, Hu B (2020) Neurologic manifestations of hospitalized patients with coronavirus disease 2019 in Wuhan, China. JAMA Neurol 77:683-690. https://doi.org/10. 1001/jamaneurol.2020.1127

33. Vaira LA, Salzano G, Deiana G, De Riu G (2020) Anosmia and ageusia: common findings in COVID-19 patients. Laryngoscope 130:1787. https://doi.org/10.1002/lary.28692

34. Spallazzi M, Morelli N, Taga A (2020) COVID-19 and neurologic manifestations: a still missing link and a call for neurologists. Neurol Sci 41:1997-1998. https://doi.org/10.1007/s10072-02004540-0

35. Zhou Z, Kang H, Li S, Zhao X (2020) Understanding the neurotropic characteristics of SARS-CoV-2: from neurological manifestations of COVID-19 to potential neurotropic mechanisms. J Neurol 267:2179-2184. https://doi.org/10.1007/s00415-020-09929-7

36. Xu J, Lazartigues E (2020) Expression of ACE2 in human neurons supports the neuro-invasive potential of COVID-19 virus. Cell Mol Neurobiol. https://doi.org/10.1007/s10571-020-00915-1

37. Karadas O, Ozturk B, Sonkaya AR (2020) A prospective clinical study of detailed neurological manifestations in patients with COVID-19. Neurol Sci 41:1991-1995. https://doi.org/10.1007/ s10072-020-04547-7

38. Hesdorffer DC (2016) Comorbidity between neurological illness and psychiatric disorders. CNS Spectr 21:230-238. https://doi. org/10.1017/S1092852915000929

39. Kanner AM, Ribot R, Mazarati A (2018) Bidirectional relations among common psychiatric and neurologic comorbidities and epilepsy: do they have an impact on the course of the seizure disorder? Epilepsia Open 3:210-219. https://doi.org/10.1002/epi4.12278

40. Niazkar HR, Zibaee B, Nasimi A, Bahri N (2020) The neurological manifestations of COVID-19: a review article. Neurol Sci 41:16671671. https://doi.org/10.1007/s10072-020-04486-3

41. DosSantos MF, Devalle S, Aran V, Capra D, Roque NR, CoelhoAguiar JM, Spohr T, Subilhaga JG, Pereira CM, D'Andrea Meira I, Niemeyer Soares Filho P, Moura-Neto V (2020) Neuromechanisms of SARS-CoV-2: a review. Front Neuroanat 14:37. https://doi.org/ 10.3389/fnana.2020.00037

42. Toljan K (2020) Letter to the editor regarding the viewpoint "Evidence of the COVID-19 virus targeting the CNS: tissue distribution, host-virus interaction, and proposed neurotropic 
mechanism". ACS Chem Neurosci 11:1192-1194. https://doi.org/ 10.1021/acschemneuro.0c00174

43. Conde Cardona G, Quintana Pajaro LD, Quintero Marzola ID, Ramos Villegas Y, Moscote Salazar LR (2020) Neurotropism of SARS-CoV 2: mechanisms and manifestations. J Neurol Sci 412: 116824. https://doi.org/10.1016/j.jns.2020.116824

44. Yachou Y, El Idrissi A, Belapasov V, Ait Benali S (2020) Neuroinvasion, neurotropic, and neuroinflammatory events of SARS-CoV-2: understanding the neurological manifestations in COVID-19 patients. Neurol Sci 41:2657-2669. https://doi.org/10. 1007/s10072-020-04575-3

45. Li Q, Guan X, Wu P, Wang X, Zhou L, Tong Y, Ren R, Leung KSM, Lau EHY, Wong JY, Xing X, Xiang N, Wu Y, Li C, Chen Q, Li D, Liu T, Zhao J, Liu M, Tu W, Chen C, Jin L, Yang R, Wang Q, Zhou S, Wang R, Liu H, Luo Y, Liu Y, Shao G, Li H, Tao Z, Yang Y, Deng Z, Liu B, Ma Z, Zhang Y, Shi G, Lam TTY, Wu JT, Gao GF, Cowling BJ, Yang B, Leung GM, Feng Z (2020) Early transmission dynamics in Wuhan, China, of novel coronavirus-infected pneumonia. N Engl J Med 382:1199-1207. https://doi.org/10.1056/ NEJMoa2001316

46. Lu R, Zhao X, Li J, Niu P, Yang B, Wu H, Wang W, Song H, Huang B, Zhu N, Bi Y, Ma X, Zhan F, Wang L, Hu T, Zhou H, Hu Z, Zhou W, Zhao L, Chen J, Meng Y, Wang J, Lin Y, Yuan J, Xie Z, Ma J, Liu WJ, Wang D, Xu W, Holmes EC, Gao GF, Wu G, Chen W, Shi W, Tan W (2020) Genomic characterisation and epidemiology of 2019 novel coronavirus: implications for virus origins and receptor binding. Lancet 395:565-574. https://doi.org/10. 1016/S0140-6736(20)30251-8

47. Gu J, Gong E, Zhang B, Zheng J, Gao Z, Zhong Y, Zou W, Zhan J, Wang S, Xie Z, Zhuang H, Wu B, Zhong H, Shao H, Fang W, Gao D, Pei F, Li X, He Z, Xu D, Shi X, Anderson VM, Leong AS (2005) Multiple organ infection and the pathogenesis of SARS. J Exp Med 202:415-424. https://doi.org/10.1084/jem.20050828

48. Romero-Sanchez CM, Diaz-Maroto I, Fernandez-Diaz E, SanchezLarsen A, Layos-Romero A, Garcia-Garcia J, Gonzalez E, Redondo-Penas I, Perona-Moratalla AB, Del Valle-Perez JA, Gracia-Gil J, Rojas-Bartolome L, Feria-Vilar I, Monteagudo M, Palao M, Palazon-Garcia E, Alcahut-Rodriguez C, SopelanaGaray D, Moreno Y, Ahmad J, Segura T (2020) Neurologic manifestations in hospitalized patients with COVID-19: the ALBACOVID registry. Neurology 95:e1060-e1070. https://doi. org/10.1212/WNL.0000000000009937

49. Liotta EM, Batra A, Clark JR, Shlobin NA, Hoffman SC, Orban ZS, Koralnik IJ (2020) Frequent neurologic manifestations and encephalopathy-associated morbidity in Covid-19 patients. Ann Clin Transl Neurol. https://doi.org/10.1002/acn3.51210

50. Shen Z, Xiao Y, Kang L, Ma W, Shi L, Zhang L, Zhou Z, Yang J, Zhong J, Yang D, Guo L, Zhang G, Li H, Xu Y, Chen M, Gao Z, Wang J, Ren L, Li M (2020) Genomic diversity of severe acute respiratory syndrome-coronavirus 2 in patients with coronavirus disease 2019. Clin Infect Dis 71:713-720. https://doi.org/10.1093/ $\mathrm{cid} / \mathrm{ciaa} 203$

51. Leonardi M, Padovani A, McArthur JC (2020) Neurological manifestations associated with COVID-19: a review and a call for action. J Neurol 267:1573-1576. https://doi.org/10.1007/s00415020-09896-Z

52. Huang C, Wang Y, Li X, Ren L, Zhao J, Hu Y, Zhang L, Fan G, Xu J, Gu X, Cheng Z, Yu T, Xia J, Wei Y, Wu W, Xie X, Yin W, Li H, Liu M, Xiao Y, Gao H, Guo L, Xie J, Wang G, Jiang R, Gao Z, Jin Q, Wang J, Cao B (2020) Clinical features of patients infected with 2019 novel coronavirus in Wuhan, China. Lancet 395:497-506. https://doi.org/10.1016/S0140-6736(20)30183-5

53. Guan WJ, Ni ZY, Hu Y, Liang WH, Ou CQ, He JX, Liu L, Shan H, Lei CL, DSC H, Du B, Li LJ, Zeng G, Yuen KY, Chen RC, Tang
CL, Wang T, Chen PY, Xiang J, Li SY, Wang JL, Liang ZJ, Peng YX, Wei L, Liu Y, Hu YH, Peng P, Wang JM, Liu JY, Chen Z, Li G, Zheng ZJ, Qiu SQ, Luo J, Ye CJ, Zhu SY, Zhong NS, China Medical Treatment Expert Group for C (2020) Clinical characteristics of coronavirus disease 2019 in China. N Engl J Med 382: 1708-1720. https://doi.org/10.1056/NEJMoa2002032

54. Rodriguez-Morales AJ, Cardona-Ospina JA, Gutierrez-Ocampo E, Villamizar-Pena R, Holguin-Rivera Y, Escalera-Antezana JP, Alvarado-Arnez LE, Bonilla-Aldana DK, Franco-Paredes C, Henao-Martinez AF, Paniz-Mondolfi A, Lagos-Grisales GJ, Ramirez-Vallejo E, Suarez JA, Zambrano LI, Villamil-Gomez WE, Balbin-Ramon GJ, Rabaan AA, Harapan H, Dhama K, Nishiura H, Kataoka H, Ahmad T, Sah R, Latin American Network of Coronavirus Disease C-REahwlo (2020) Clinical, laboratory and imaging features of COVID-19: a systematic review and meta-analysis. Travel Med Infect Dis 34:101623. https://doi. org/10.1016/j.tmaid.2020.101623

55. Wang D, Hu B, Hu C, Zhu F, Liu X, Zhang J, Wang B, Xiang H, Cheng Z, Xiong Y, Zhao Y, Li Y, Wang X, Peng Z (2020) Clinical characteristics of 138 hospitalized patients with 2019 novel coronavirus-infected pneumonia in Wuhan, China. JAMA 323: 1061-1069. https://doi.org/10.1001/jama.2020.1585

56. Wang Z, Yang B, Li Q, Wen L, Zhang R (2020) Clinical features of 69 cases with coronavirus disease 2019 in Wuhan, China. Clin Infect Dis 71:769-777. https://doi.org/10.1093/cid/ciaa272

57. Chen N, Zhou M, Dong X, Qu J, Gong F, Han Y, Qiu Y, Wang J, Liu Y, Wei Y, Xia J, Yu T, Zhang X, Zhang L (2020) Epidemiological and clinical characteristics of 99 cases of 2019 novel coronavirus pneumonia in Wuhan, China: a descriptive study. Lancet 395:507-513. https://doi.org/10.1016/S01406736(20)30211-7

58. Oxley TJ, Mocco J, Majidi S, Kellner CP, Shoirah H, Singh IP, De Leacy RA, Shigematsu T, Ladner TR, Yaeger KA, Skliut M, Weinberger J, Dangayach NS, Bederson JB, Tuhrim S, Fifi JT (2020) Large-vessel stroke as a presenting feature of Covid-19 in the young. N Engl J Med 382:e60. https://doi.org/10.1056/ NEJMc2009787

59. Emami A, Fadakar N, Akbari A, Lotfi M, Farazdaghi M, Javanmardi F, Rezaei T, Asadi-Pooya AA (2020) Seizure in patients with COVID-19. Neurol Sci 19:1-5. https://doi.org/10.1007/ s10072-020-04731-9

60. Giacomelli A, Pezzati L, Conti F, Bernacchia D, Siano M, Oreni L, Rusconi S, Gervasoni C, Ridolfo AL, Rizzardini G, Antinori S, Galli M (2020) Self-reported olfactory and taste disorders in patients with severe acute respiratory coronavirus 2 infection: a cross-sectional study. Clin Infect Dis 71:889-890. https://doi.org/ $10.1093 / \mathrm{cid} / \mathrm{ciaa} 330$

61. Vaira LA, Deiana G, Fois AG, Pirina P, Madeddu G, De Vito A, Babudieri S, Petrocelli M, Serra A, Bussu F, Ligas E, Salzano G, De Riu G (2020) Objective evaluation of anosmia and ageusia in COVID-19 patients: single-center experience on 72 cases. Head Neck 42:1252-1258. https://doi.org/10.1002/hed.26204

62. Chen R, Liang W, Jiang M, Guan W, Zhan C, Wang T, Tang C, Sang L, Liu J, Ni Z, Hu Y, Liu L, Shan H, Lei C, Peng Y, Wei L, Liu Y, Hu Y, Peng P, Wang J, Liu J, Chen Z, Li G, Zheng Z, Qiu S, Luo J, Ye C, Zhu S, Liu X, Cheng L, Ye F, Zheng J, Zhang N, Li Y, He J, Li S, Zhong N, Medical Treatment Expert Group for C (2020) Risk factors of fatal outcome in hospitalized subjects with coronavirus disease 2019 from a cationwide analysis in China. Chest 158: 97-105. https://doi.org/10.1016/j.chest.2020.04.010

63. Zhang JJ, Dong X, Cao YY, Yuan YD, Yang YB, Yan YQ, Akdis CA, Gao YD (2020) Clinical characteristics of 140 patients infected with SARS-CoV-2 in Wuhan, China. Allergy 75:1730-1741. https://doi.org/10.1111/all.14238 
64. Jordan RE, Adab P, Cheng KK (2020) Covid-19: risk factors for severe disease and death. BMJ 368:m1198. https://doi.org/10.1136/ bmj.m1198

65. Ludvigsson JF (2020) Systematic review of COVID-19 in children shows milder cases and a better prognosis than adults. Acta Paediatr 109:1088-1095. https://doi.org/10.1111/apa.15270

66. Dugue R, Cay-Martinez KC, Thakur KT, Garcia JA, Chauhan LV, Williams SH, Briese T, Jain K, Foca M, McBrian DK, Bain JM, Lipkin WI, Mishra N (2020) Neurologic manifestations in an infant with COVID-19. Neurology 94:1100-1102. https://doi.org/10. 1212/WNL.0000000000009653
67. Saini AG, Suthar R (2020) COVID-19 pandemic: the concerns of pediatric neurologists. Ann Indian Acad Neurol 23:358-359. https://doi.org/10.4103/aian.AIAN_407_20

68. Abdel-Mannan O, Eyre M, Lobel U, Bamford A, Eltze C, Hameed B, Hemingway C, Hacohen Y (2020) Neurologic and radiographic findings associated with COVID-19 infection in children. JAMA Neurol. https://doi.org/10.1001/jamaneurol. 2020.2687

Publisher's note Springer Nature remains neutral with regard to jurisdictional claims in published maps and institutional affiliations. 